\title{
Prevalence and factors affecting disclosure of HIV status among pregnant women attending antenatal care in Addis Ababa public health centres: a cross sectional survey
}

\begin{abstract}
Background: In Ethiopia a little has been explored about the prevalence of, barriers to, outcomes and factors associated with HIV status disclosure among HIV positive pregnant women. Objective: To assess factors of disclosing HIV sero-status to sexual partner among HIV positive pregnant women attending antenatal care in Addis Ababa public health centers, Ethiopia.

Method: An institution based Cross- sectional study was conducted using quantitative method among 665 HIV positive pregnant women who were attending antenatal care from May 1-30/2016. All sero-positive pregnant women of age $\geq 18$ years were included in study by multistage sampling method. Data was collected using structured interviewer administered questionnaire and entered and analyzed by SPSS 20 version. Multivariate logistic regressions were applied to evaluate significant association between independent and outcome (HIV positive sero-status disclosure).

Result: a total of 665 HIV positive pregnant women, participated in the study with the response rate of $99 \%$. The overall Prevalence of disclosure of HIV status among pregnant women is $80.6 \%$ and $51.7 \%$ disclosed to their current main sexual partner. However, $35.2 \%$ of disclosure to sexual partner was delayed and $13.5 \%$ didn't know their participant HIV status. Disclosure of HIV status to sexual partner was associated with discussion about HIV testing with partner prior to test (OR, 2.594, 95\%CI, 1.474-4.565) and knowing partner HIV status (having sero-positive partner) (OR, 0.409, 95\% CI, 0.231-0.723). Conclusion: nearly half of the women challenged to disclose their status due to lack of open discussion with their partners that might lead to limited ability to engage in preventive behaviors and to access support.
\end{abstract}

Keywords: HIV, sero-status, pregnant, disclosure, sexual partner
Volume 10 Issue 4 - 2019

\author{
Yodit Meseret,' Dubale Dulla, ${ }^{2}$ Banchialem \\ $\mathrm{Nega}^{3}$ \\ 'MNCH project, Ethio-Canada, Ethiopia \\ ${ }^{2}$ Department of Midwifery, College of medicine and health \\ science, Hawassa University, Ethiopia \\ ${ }^{3}$ Department of Midwifery, College of medicine and health \\ science, Wolayita Soddo University, Ethiopia
}

\begin{abstract}
Correspondence: Dubale Dulla, Hawassa University, college of medicine and health science, department of Midwifery, Hawassa,
\end{abstract} Ethiopia, +25I913850895, Email dzmhkb2012@gmail.com

Received: July 05, 2019 | Published: August 27, 2019

\begin{abstract}
Abbreviations: AIDS, acquired immune deficiency syndrome; ANC, antenatal care; AOR, adjusted odds ratio; ART, antiretroviral therapy; $\mathrm{B}^{+}$, using a single tablet fixed dose combination of tenofovir, lamivudine and efavirenz; CART, combined antiretroviral treatment; CARV, combined antiretroviral therapy; CD4, cluster of differentiations 4; CI, confidence interval; COR, crude odds ratio; HCT, HIV counselling and testing; HIV, human immune deficiency virus; OR, odds ratio; PLWHIV, people living with HIV; PMTCT, prevention of mother to child transmission; SD, standard deviation; SPSS, statistical package for social sciences; WHO, World health organization
\end{abstract}

\section{Introduction}

The prevention of HIV infection depends on the success of strategies to prevent new infection and treat currently infected individuals. Prevention of mother to child transmission (PMTCT) and HIV counseling and testing (HCT) services are both a critical prevention and treatment tools in controlling HIV epidemics. Within PMTCT and HCT program emphasis is placed on the importance of HIV status disclosure among HIV infected clients, particularly their sexual partners.

Disclosure of HIV status to sexual partner is an important prevention goal emphasized by the WHO and centers for disease control and prevention in their protocols for HIV testing and counseling. Besides it offers a number of important benefits to the infected individual and the general public. ${ }^{2-5}$ Some of potential benefits for the individual and public including increased opportunities for social support, improved access to necessary medical care (antiretroviral treatment), increased opportunities to discuss and implement HIV risk reduction with partners, and increased opportunities to plan for the future, motivating sexual partners to be tested, change bad behaviours, reduce vertical and sexual transmission risk..$^{7-12}$

Consequently, Women who disclose their HIV sero-status to their sexual partners may be more likely to participate in programmes for prevention of HIV transmission to their sexual partners as well as to their infants. ${ }^{13}$ in addition, it enables couples to make informed reproductive health choices that may ultimately lower the number of unintended pregnancies among HIV positive women and help them take ARV drugs properly and give it to the new born as recommended by physicians..$^{14}$

Despite, all the mentioned benefits, HIV infected women may face a lot of potential risks following disclosure: including loss of economic support, blame, abandonment, physical and emotional abuse, discrimination and disruption of family relationships. ${ }^{14,15}$ Fear of the above these risks identified as barriers to disclose their serostatus for immediate partners ${ }^{16,17}$ that in turn lead to lost opportunities 
for the prevention of new infections and ability to access appropriate treatment, care and support services where they are available. ${ }^{18,19}$ Despite the availability and scale up of life-saving interventions, in Ethiopia only $24 \%$ of pregnant women living with HIV are receiving the medication to prevent mother-to-child transmission of HIV. ${ }^{4}$ Because, the uptake and adherence to PMTCT programmes is difficult for women whose partners are unaware of their HIV status. This study was intended to assess issues of disclosing HIV sero-status among HIV positive pregnant women attending antenatal care in public health centres of Addis Ababa.

\section{Methods}

\section{Study setting}

Institution based cross sectional study was conducted among HIV+ pregnant women attending ANC service in selected public health centres that are providing PMTCT services in Addis Ababa. Addis Ababa is a capital city of Ethiopia. The city covers an area of 530.14 square kilometres that is divided into 10 sub-cities ("Kifle Ketema") and 100 kebeles with an estimated population of $3,384,569 .{ }^{20}$ There are about 29 hospitals, 82 health centres, 8 health stations and 116 health posts owned by public and private, of which 5 hospitals, 24 health centres and 8 health posts are governmental.

\section{Inclusion and exclusion criteria}

HIV positive pregnant women of age $\geq 18$ years, who attended ANC follow up and undergone HIV counselling, testing and received their HIV test result before one month prior to study were included. However, those who were seriously ill and unable to communicate and those with age of $<18$ are excluded from the study.

\section{Sample size and sampling procedures}

The sample size was computed using Open Epi version 3 (Kelsy, et al) by considering the following assumptions: $n=$ sample size, $\mathrm{z}=$ standard normal deviate set at 1.96 (for $95 \%$ confidence level), $\mathrm{d}=$ desired degree of accuracy $(0.05)$ and by taking the proportion of sero status disclosure from Addis Ababa which was $73 \%{ }^{5}$ and design effect of 2 .

After identification of $78 \mathrm{HCs}$ providing PMTCT service, health centres are clustered by sub-cities and one health centre was selected from each sub cities by simple random sampling and the sample size was distributed to study population of respective health centres. Finally, a total of 668 pregnant women were selected by systemic random sampling using PMTCT register book as sampling framework. All eligible participants were interviewed.

\section{Data collection and analysis}

Data were collected using structured and pre-tested interviewer questionnaire IN Amharic version accommodating: sociodemographic characteristics (age, income, education, religion and occupation), relationship factors (duration of relationship, fear of partner's reaction and HIV status of partner), barriers to HIV Status disclosure (fear of abandonment, fear of confidentiality, and fear of accusation of infidelity) and Outcome of disclosure (acceptance, understanding, blame and violence). The collected data was cleaned, checked, coded, entered and then analysed by version 20 Statistical Package (SPSS) software. Bivariate and multivariate analysis was carried out to see the effect of each factor. Variables that showed significant association in the bivariate analyses were fitted in to a multiple logistic regression model to identify the independent contribution of each variable for HIV sero-positive status disclosure. Odds ratio with $95 \%$ confidence interval was calculated to assess both the association and measure the strength of the association between explanatory and outcome variables. P-Value 0.2 or less was taken as a cut-off point to include the variable in to the final model.

\section{Ethical consideration}

Ethical clearance was obtained from ethical review committee of Debre-markos University Medicine and Health science collage. Letter of agreement was obtained to Addis Ababa health bureau and Addis Ababa health bureau approved it to be continued. Informed consent was granted by individual respondent at the time of data collection. Privacy and confidentiality of participants were maintained throughout the study.

\section{Result}

\section{Socio demographic characteristics of the participants}

A total of 665 pregnant women were interviewed making a response rate of $99 \%$. Among all participants, 328 (49.3\%) were in age group of 28-32 years, 228 (34.3\%) Amhara by ethnicity, $345(51.9 \%)$ were of Orthodox religion, $202(30.4 \%)$ were unable to read and write, 273(41.1\%) house wife, $459(69 \%)$ were married and house hold income between 600-1600 were 313(47.1\%) (Table 1).

\section{Obstetric, Sexual and clinical characteristics of participants}

Most pregnant mothers 435(65.4\%) have early first trimester pregnancy, 224(33.7\%) has ANC follow up more than 3 times, 473 (71.4\%) know HIV positive pregnant women transmits the virus to her unborn baby, 505(75.9\%) mothers know the existence of HIV transmission intervention, whereas 49(7.4\%) mothers didn't know the benefit of ART drugs.

As Table 2 shows, three hundred eighty (57.1\%) claim disclosing their result to anyone could affect ANC follow up, 7(1.1\%) mothers didn't know it might affect or not. Among all participants, 148(22.3\%) didn't use condom because they found it difficult to discuss about condom with their sexual partner while $3(0.5 \%)$ found it difficult to put it on or use it properly.

\section{HIV status disclosure}

Among all respondents $536(80.6 \%)$ indicated that they have disclosed their result to at least one individual. However; of those who disclosed $234(35.2 \%)$ of women had sex with their partner before telling their result. Respondents reported disclosing most frequently to main partners $(51.7 \%)$ followed by mother $(20.2 \%)$, other family members $(4.8 \%)$ (Table 3$)$.

\section{Reasons for disclosure and/or non-disclosure}

The first motivating reason for disclosure of their HIV status reported by participants was seeking support from their partner $102(29.1 \%)$. While $64(18.3 \%)$ of respondents disclosed their test result to keep free their partner. Having a close relationship (usual to tell him every secret thing), spiritual responsibility and fear of legal accusation were the other motivators of disclosure. On other sides, reasons for non-disclosure among those respondents who did not disclose their test results to their partner, were fear of physically being hurt by partner 170(25.6\%), separation/divorce 163(31.8\%), 
fear of labelling as bad person $5(1.0 \%)$, he might be afraid of risk of HIV infection from me $9(1.8 \%)$, my partner might get angry with me 16(3.2\%), and other reasons depicted in Table 4.

Table I Socio demographic characteristics of participants in Addis Ababa public health centres, 2016

\begin{tabular}{|c|c|c|c|}
\hline Variables & Category & $\begin{array}{l}\text { Number } \\
(\mathrm{N}=665)\end{array}$ & Percent \\
\hline \multirow{5}{*}{ Age(years) } & $18-22$ & 92 & 13.8 \\
\hline & $23-27$ & 197 & 29.6 \\
\hline & $28-32$ & 328 & 49.3 \\
\hline & $33-37$ & 41 & 6.2 \\
\hline & $>=38$ & 7 & I.I \\
\hline \multirow{5}{*}{ Education } & Unable to read and write & 202 & 30.4 \\
\hline & Gradel-4 & 98 & 14.7 \\
\hline & Grade 5-8 & 186 & 28 \\
\hline & Grade $9-12$ & 147 & 22.1 \\
\hline & College and above & 32 & 4.8 \\
\hline \multirow{5}{*}{ Ethnicity } & Amhara & 228 & 34.3 \\
\hline & Oromo & 212 & 31.9 \\
\hline & Tigre & 66 & 9.9 \\
\hline & Gurage & 111 & 16.7 \\
\hline & other* & 48 & 7.2 \\
\hline \multirow{4}{*}{ Religion } & Orthodox & 345 & 51.9 \\
\hline & Muslim & 184 & 27.7 \\
\hline & Protestant & 123 & 18.5 \\
\hline & Catholic & 13 & 2 \\
\hline \multirow{7}{*}{ Employment } & Government employ & 67 & 10.1 \\
\hline & Private employee & 103 & 15.5 \\
\hline & Housewife & 273 & $4 I .1$ \\
\hline & Daily labourer & 115 & 17.3 \\
\hline & Merchant & 52 & 7.8 \\
\hline & Commercial sex worker & 7 & 1.1 \\
\hline & other** & 48 & 7.2 \\
\hline \multirow{4}{*}{ Marital status } & Single & 130 & 19.5 \\
\hline & Married & 459 & 69 \\
\hline & Divorced & 59 & 8.9 \\
\hline & Widowed & 17 & 2.6 \\
\hline \multirow{5}{*}{$\begin{array}{l}\text { Household } \\
\text { income }\end{array}$} & $<600$ birr/month & 93 & 14 \\
\hline & 600-1600birr/month & 313 & 47.1 \\
\hline & I60I-260 | birr/month & 107 & 16.1 \\
\hline & 2602-3602birr/month & 74 & $\mathrm{II} . \mathrm{I}$ \\
\hline & $>=3603 \mathrm{birr} / \mathrm{month}$ & 78 & 11.7 \\
\hline
\end{tabular}

Table 2 Obstetric, Sexual and clinical characteristics of the respondents, Addis Ababa public health centres, 2016

\begin{tabular}{|c|c|c|c|}
\hline Variable & & Number & Percent \\
\hline \multirow{2}{*}{$\begin{array}{l}\text { Counselled before } \\
\text { test }\end{array}$} & Yes & 634 & 95.3 \\
\hline & No & 31 & 4.7 \\
\hline \multirow{2}{*}{ Counselled after test } & Yes & 621 & 93.4 \\
\hline & No & 44 & 6.6 \\
\hline \multirow{2}{*}{ Counselled and tested } & Individually & 495 & 74.4 \\
\hline & With couple & 170 & 25.6 \\
\hline \multirow{2}{*}{$\begin{array}{l}\text { Know presence of } \\
\text { ARV in ANC }\end{array}$} & Yes & 264 & 39.7 \\
\hline & No & 401 & 60.3 \\
\hline \multirow{2}{*}{ Currently on ART } & Yes & 645 & 97 \\
\hline & No & 20 & 3 \\
\hline \multirow{4}{*}{$\begin{array}{l}\text { WHO Stage of } \\
\text { disease at enrolment }\end{array}$} & Stage I & 326 & 49 \\
\hline & Stage 2 & 252 & 37.9 \\
\hline & Stage 3 & 83 & 12.5 \\
\hline & Stage 4 & 4 & 0.6 \\
\hline \multirow{2}{*}{$\begin{array}{l}\text { Condom use at last } \\
\text { sexual intercourse }\end{array}$} & Yes & 204 & 30.7 \\
\hline & No & 461 & 69.3 \\
\hline \multirow{6}{*}{$\begin{array}{l}\text { Reasons for not using } \\
\text { condom }\end{array}$} & $\mathrm{He}$ is HIV positive & 102 & 15.3 \\
\hline & $\begin{array}{l}\text { Condom take } \\
\text { romance away }\end{array}$ & 32 & 4.8 \\
\hline & $\begin{array}{l}\text { Partner Suspicious } \\
\text { of my positive status }\end{array}$ & 77 & 11.6 \\
\hline & $\begin{array}{l}\text { Found it difficult to } \\
\text { use/put on }\end{array}$ & 3 & 0.5 \\
\hline & $\begin{array}{l}\text { Found it difficult to } \\
\text { discuss condom use } \\
\text { with partner }\end{array}$ & 148 & 22.3 \\
\hline & Other & 124 & 18.6 \\
\hline \multirow{4}{*}{$\begin{array}{l}\text { Condom use since } \\
\text { HIV positive diagnosis }\end{array}$} & Always & 152 & 22.9 \\
\hline & Most of the time & 60 & 9 \\
\hline & Sometimes & 37 & 5.6 \\
\hline & Don't use at all & 416 & 62.6 \\
\hline
\end{tabular}

\section{Reaction main partners towards HIV status disclosure among HIV positive women}

As represented in Table 5, 25.3\% anticipated that their partner would be supportive and actually $27.4 \%$ of partners were supportive towards disclosure. However, some of the partners reacted with unwanted reaction such as anger 15(2.3\%), confused 131(19.7\%) and leave the relationship 1(0.2\%). Even though there were eight participants who anticipated physical violence, there was only three individual physically harmed. 
Table 3 HIV status disclosures among HIV positive women Addis Ababa public health centres April, 2016

\begin{tabular}{llll}
\hline Variable & & Number & Percent \\
\hline $\begin{array}{llll}\text { Disclosed the result } \\
\text { to any one }(\mathrm{N}=665)\end{array}$ & Yes & 536 & 80.6 \\
& No & 129 & 19.4 \\
& Family member & 26 & 51.7 \\
& Mother & 277 & 4.8 \\
$\begin{array}{l}\text { Disclosed the result } \\
\text { to }(\mathrm{N}=536)\end{array}$ & Fathers & 108 & 20.2 \\
& children & 43 & 8.1 \\
& Others & 13 & 2.4 \\
& Yes & 69 & 12.9 \\
\hline
\end{tabular}

Table 4 Reasons respondent to disclose and/or not disclosing HIV status to their sexual partner,Addis Ababa public health centres, 2016

\begin{tabular}{|c|c|c|}
\hline Reason for disclosure & Numbers & Percent \\
\hline No secret between couples & 106 & 30.3 \\
\hline To get partner's support & 102 & 29.1 \\
\hline Don't want to put partner at risk & 64 & 18.3 \\
\hline Fear of God & 27 & 7.7 \\
\hline Tested together & 12 & 3.4 \\
\hline Other & 39 & II.I \\
\hline \multicolumn{3}{|l|}{ Reason for not disclosing } \\
\hline He might leave me & 163 & 31.8 \\
\hline He might think I am a bad person & 5 & I \\
\hline $\begin{array}{l}\text { He might be afraid of catching HIV from } \\
\text { me }\end{array}$ & 9 & 1.8 \\
\hline The person might think I am Unfaithful & 53 & 10.4 \\
\hline He might hurt me physically & 170 & 33.3 \\
\hline He might get angry with me & 16 & 3.2 \\
\hline He may tell others & 74 & 14.5 \\
\hline I do not want to worry him & 21 & 4.1 \\
\hline $\mathrm{He}$ is too young to handle it & 12 & 2.4 \\
\hline Until I got sick I don't want to tell him & 5 & I \\
\hline He has his own problems to think about & 17 & 3.4 \\
\hline He might kill me if he found out & 51 & 10.1 \\
\hline
\end{tabular}

\section{Determinants of sero-status disclosure}

As shown in Table 6, in bivariate analysis some of the variables were found to be significantly associated with HIV status disclosure of pregnant women. Among socio-demographic characteristics those having smooth relationship with partners and expecting long lasting relationship were significantly associated with disclosure of their status. Whereas educational status, marital status and employment status was not significantly associated. Besides, some of service related factors were found to be associated with disclosure. Participants, who discussed about HIV prior to test, talking about testing together, know partners HIV status and having relationship for more than four years were variables more likely to disclose their result to partners than those who didn't.

Table 5 Anticipated versus actual main partner's reaction towards HIV status disclosure among HIV positive women, Addis Ababa public health centres, 2016

\begin{tabular}{lll}
\hline Partners reaction & Anticipated & Actual \\
\hline Supportive & $168(25.3)$ & $182(27.4)$ \\
Assure me & $93(14)$ & $144(21.7)$ \\
Confused & $110(16.5)$ & $131(19.7)$ \\
Angry & $38(5.7)$ & $15(2.3)$ \\
Worry about his own HIV status & $35(5.3)$ & $46(6.9)$ \\
Talk about leaving the relation ship & $46(6.9)$ & $8(1.2)$ \\
Leave the relation ship & $6(0.9)$ & $1(0.2)$ \\
Ask about my sexual history & $35(5.3)$ & $34(5.1)$ \\
Take care of me & $51(7.7)$ & $54(8.1)$ \\
Beat me up & $8(1.2)$ & $3(0.5)$ \\
Cry & $16(2.4)$ & $60(9)$ \\
Threaten me & $23(3.5)$ & $4(6)$ \\
\hline
\end{tabular}

Multiple logistic regressions was employed to control potential confounders. Important variables bivariate P-value 0.2 or less was included to the model. In the multiple logistic regression analysis models two variables were found to be independent predictors of disclosure to a partner (Table 7). Those participants who didn't know their partners HIV status were $59.1 \%$ less likely to disclose their serostatus than those who know their partners result (having seropositive partner) (OR, 0.409, 95\%CI, 0.231-0.723). Individuals who have prior discussion about HIV testing with partner were 2.5 times more likely to disclose their status than those who didn't have discussion previously(OR,2.594,95\%CI, 1.474-4.565). 
Table 6 Factors associated with HIV status disclosure among HIV positive women,Addis Ababa public health centres, 2016

\begin{tabular}{|c|c|c|c|c|}
\hline Variables & Disclosed number (\%) & Not disclosed number (\%) & $\operatorname{COR}(95 \% \mathrm{Cl})$ & P-Value \\
\hline \multicolumn{5}{|l|}{ Educational status } \\
\hline Educated & $376(81.2 \%)$ & $87(18.8 \%)$ & $1.134(0.75|-1.7| 3)$ & \multirow{2}{*}{0.548} \\
\hline Not educated & $160(79.2 \%)$ & $42(20.8 \%)$ & 1.00 & \\
\hline \multicolumn{5}{|l|}{ Marital status } \\
\hline Married & $374(81.5 \%)$ & $85(18.5 \%)$ & I.195(0.795-I.797) & \multirow{2}{*}{0.392} \\
\hline Not married & $162(78.6 \%)$ & $44(21.4 \%)$ & 1.00 & \\
\hline \multicolumn{5}{|c|}{ Relationship before test } \\
\hline Smooth relationship & $225(85.2 \%)$ & $39(14.8 \%)$ & $1.65 \mathrm{I}(1.109-2.538)$ & \multirow{2}{*}{0.014} \\
\hline Disagreement & $3 \mathrm{II}(77.6 \%)$ & $89(22.4 \%)$ & 1.00 & \\
\hline \multicolumn{5}{|c|}{ Employments status } \\
\hline Employed & $287(82.0 \%)$ & $63(18.0 \%)$ & I.207(0.822-1.774) & \multirow{2}{*}{0.337} \\
\hline Unemployed & $249(79.0 \%)$ & $66(21.0 \%)$ & 1.00 & \\
\hline \multicolumn{5}{|c|}{ Expectation About relation } \\
\hline Long lasting & $269(84.3 \%)$ & $50(15.7 \%)$ & I.592(I.075-2.357) & \multirow{2}{*}{0.02} \\
\hline Short lasting & $267(77.2 \%)$ & $79(22.8 \%)$ & 1.00 & \\
\hline \multicolumn{5}{|l|}{ Type of counselling } \\
\hline Couple & $48 I(8 I .1 \%)$ & $\mathrm{II}(\mathrm{I} 8.9 \%)$ & I.327(0.742-2.374) & \multirow{2}{*}{0.34} \\
\hline Individual & $55(76.4 \%)$ & $17(23.6 \%)$ & 1.00 & \\
\hline \multicolumn{5}{|c|}{ Residing in the same house } \\
\hline Yes & $442(80.1 \%)$ & $110(19.9 \%)$ & $0.812(0.475-1.387)$ & \multirow{2}{*}{0.446} \\
\hline No & $94(83.2 \%)$ & $19(16.8 \%)$ & 1.00 & \\
\hline \multicolumn{5}{|c|}{ Discuss about HIV with partner } \\
\hline Yes & $272(85.5 \%)$ & $46(14.5 \%)$ & $1.859(1.249-2.768)$ & \multirow{2}{*}{$0.002^{*}$} \\
\hline No & $264(76.1 \%)$ & $83(23.9 \%)$ & 1.00 & \\
\hline \multicolumn{5}{|c|}{ Talked about testing with partner before test } \\
\hline Yes & $188(90.4 \%)$ & $20(9.6 \%)$ & 2.944(I.770-4.897) & \multirow{2}{*}{$0.000 *$} \\
\hline No & $348(76.1 \%)$ & $109(23.9 \%)$ & 1.00 & \\
\hline \multicolumn{5}{|c|}{ Know partner's HIV status } \\
\hline Yes & $268(86.5 \%)$ & $42(13.5 \%)$ & $2.07 \mid(1.38 \mid-3.107)$ & \multirow{2}{*}{$0.000^{*}$} \\
\hline No & $268(75.5 \%)$ & $87(24.5 \%)$ & 1.00 & \\
\hline \multicolumn{5}{|c|}{ Partner's HIV status } \\
\hline Positive & $45(86.5 \%)$ & $7(13.5 \%)$ & I.029(0.43I-2.457) & \multirow{2}{*}{0.949} \\
\hline Negative & $225(86.2 \%)$ & $36(13.8 \%)$ & 1.00 & \\
\hline \multicolumn{5}{|c|}{ WHO stage of diseases } \\
\hline Stage I \&2 & $466(80.6)$ & $\mathrm{II} 2(19.4 \%)$ & $1.010(0.572-1.784)$ & \multirow{2}{*}{0.971} \\
\hline Stage $3 \& 4$ & $70(80.5 \%)$ & $17(19.5 \%)$ & 1.00 & \\
\hline \multicolumn{5}{|c|}{ Duration of relationship } \\
\hline$<4$ years & $24 I(39.3 \%)$ & $373(60.7 \%)$ & I.708(0.904-3.225) & \multirow{2}{*}{0.099} \\
\hline$>4$ years & |4(27.5\%) & & 1.00 & \\
\hline
\end{tabular}

*show significant association

Citation: Meseret Y, Dulla D, Nega B. Prevalence and factors affecting disclosure of HIV status among pregnant women attending antenatal care in Addis Ababa public health centres: a cross sectional survey. Obstet Gynecol Int J. 2019;10(4):3 I7-324. DOI: I0.15406/ogij.2019.10.00460 
Table 7 Predictors of disclosure of HIV-positive test result to a partner among HIV positive women,Addis Ababa,April, 2016

\begin{tabular}{|c|c|c|c|c|}
\hline Variables & $\begin{array}{l}\text { Disclosed number } \\
(\%)\end{array}$ & $\begin{array}{l}\text { Not disclosed } \\
\text { number (\%) }\end{array}$ & Crude OR(95\%Cl) & $\begin{array}{l}\text { Adjusted } \\
\text { OR(95\%CI) }\end{array}$ \\
\hline \multicolumn{5}{|c|}{ Relationship before test } \\
\hline Smooth relationship & $225(85.2 \%)$ & $39(\mid 4.8 \%)$ & $1.65 \mathrm{I}(\mathrm{I} .109-2.538)^{*}$ & \multirow{3}{*}{$1.419(0.853-2.361)$} \\
\hline & & & & \\
\hline Disagreement & $31 \mathrm{I}(77.6 \%)$ & $89(22.4 \%)$ & 1 & \\
\hline \multicolumn{5}{|c|}{ Expectation about relation } \\
\hline Long lasting & $269(84.3 \%)$ & $50(15.7 \%)$ & $1.592(1.075-2.357) *$ & \multirow{3}{*}{$1.303(0.8 .3-2.115)$} \\
\hline & & & & \\
\hline Short lasting & $267(77.2 \%)$ & $79(22.8 \%)$ & 1 & \\
\hline \multicolumn{5}{|c|}{ Discuss about HIV with partner } \\
\hline Yes & $272(85.5 \%)$ & $46(14.5 \%)$ & $1.859(1.249-2.768) *$ & \multirow{3}{*}{$0.794(0.508-I .242)$} \\
\hline & & & & \\
\hline No & $264(76.1 \%)$ & $83(23.9 \%)$ & I & \\
\hline \multicolumn{5}{|c|}{ Talked about testing with partner before test } \\
\hline Yes & $188(90.4 \%)$ & $20(9.6 \%)$ & $2.944(1.770-4.897)^{*}$ & \multirow{3}{*}{$2.594(1.474-4.565)^{* *}$} \\
\hline & & & & \\
\hline No & $348(76.1 \%)$ & $109(23.9 \%)$ & 1 & \\
\hline \multicolumn{5}{|c|}{ Know partners' HIV status } \\
\hline Yes & $268(86.5 \%)$ & $42(13.5 \%)$ & $2.07 \mid(\mid .38 I-3.107)^{*}$ & \multirow{3}{*}{$0.409(0.231-0.723)^{* *}$} \\
\hline & & & & \\
\hline No & $268(75.5 \%)$ & $87(24.5 \%)$ & I & \\
\hline \multicolumn{5}{|c|}{ Duration of relationship } \\
\hline$>4$ years & $24 I(39.3 \%)$ & $373(60.7 \%)$ & $1.708(0.904-3.225) *$ & \multirow{3}{*}{$0.578(0.285-1.172)$} \\
\hline & & & & \\
\hline$<=4$ years & |4(27.5\%) & $37(72.5 \%)$ & I & \\
\hline
\end{tabular}

*Statistically significant at $\mathrm{p}$-value $<0.2$

**Significant after adjusted for other variables $\mathrm{p}$-value $<0.05$

\section{Discussion}

The study focused on identifying factors of HIV status disclosure to sexual partner among HIV positive pregnant women in Addis Ababa public health centres. The overall prevalence of disclosure (told to at least one person) in this study was $80.6 \%$, which is less as compared to findings of study conducted in south west Ethiopia and Hawassa referral hospital (94.5\%) and (92.2\%) women disclosed their result to at least one person respectively. ${ }^{16,21}$ This difference may be due to those studies were carried out among all sero positive clients and among ART clinic customers. Because, whatever the result becomes they accepted it easily than those participants found in this study. However, participants of this research went to clinic to know the health of their unborn child as well as their own and they didn't intend to be tested if PMTCT protocol not influences them to be tested.

The overall rate of disclosure is in line with study conducted in Uganda in that $83.8 \%$ had disclosed their sero-status to at least one person, ${ }^{22}$ study of South Africa $(80.0 \%)$ disclosed to one of their family ${ }^{23}$ and Kenyan study $(83 \%) .{ }^{24}$

However it is higher than the rate $(59 \%)$ found in a study conducted in South African HIV positive pregnant women. ${ }^{2}$ Still much higher than in Tanzania $(60 \%)$ of those pregnant women interviewed had disclosed to significant others. ${ }^{1}$ Similarly it's quite higher than the finding of study in Southwest Ethiopia (69\%). ${ }^{18}$ It's higher than that of study of Zimbabwe $(65.9 \%),{ }^{17}$ also higher than that of Addis Ababa study $(75 \%),{ }^{7}$ and it's greater than result of Togo's study $(60.9 \%) .{ }^{25}$ The basic predicators of the variation in rate disclosure of this study in relation of the above mentioned ones could be the time of study because some were conducted a decades ago; difference in size of samples; and setting of study.

Despite the encouraging result found in this study, substantial proportion $(35.2 \%)$ of the disclosures were delayed, these individuals had at least one sexual contact with their untold sexual partner before disclosure. It raises the possibility of transmission risk if condoms were not used and may limit the beneficial aspect of disclosure, making negotiating safer sex difficult and perhaps putting the untold partner at risk of acquiring the infection or risk of re-infection for the couples. This estimate of delayed disclosure is somewhat higher than, reported in South west Ethiopia (14.2\%), ${ }^{16}$ in Addis Ababa (12.8\%); ${ }^{7}$ in Wolidia (29\%); ${ }^{19}$ in Tanzania (15.1\%). ${ }^{26}$ Though significant number of participants concealed their HIV status for some times after knowing their test results, it may not be surprising due to high sample 
size of this study in relation to quoted ones because the sample size of our study very huge in comparison to cited findings.

However, In Ethiopia knowing the partner's HIV status was a facilitator for disclosure ${ }^{18,16,21,27}$ and it was observed that knowing partners HIV status and talked about HIV testing prior to test with partner were independent and significant predictors of HIV status disclosure this study. In the presence of high rate of HIV status disclosure, significant proportion $(53.4 \%)$ of the respondents did not know their partner's HIV status. The silence of the partners could be either acknowledging that he is already infected or emotional rejection to the partner. This finding is lower than the result of study in Kenya in which $66 \%$ reported the partner had not tested or did not know whether he had been tested. ${ }^{9}$ This might be due to participants of our study are directly involved from ANC and that of Kenyan study were enrolled until their postpartum period that may increase recall bias. In contrast the result of this study is much higher that some studies conducted in Addis Ababa (32.7\%), ${ }^{7}$ in South west Ethiopia $20.6 \%,{ }^{16}$ in Axum $12.4 \%{ }^{27}$ did not know their partner's HIV status. The most probable reason for the variation of result could be these studies accommodated both sexes of adult groups who particularly know the status before.

The reasons given for nondisclosures were fear of separation/ divorce, fear of being labelled as bad person; he might be afraid of risk of HIV infection from me, my partner might get angry with me, and fear of breach of confidentiality. Indeed, feelings of uncertainty about how partner would react to their status were mentioned by most of the participants. This was in agreement with other studies. ${ }^{16}$ This implies that individuals who know their partner's HIV status at least had a discussion time about HIV testing, and these would help them to anticipate their partner's reaction towards disclosure.

Besides, discussion with partner before test had been identified as facilitating factor of disclosure of HIV status for their intimate partners. ${ }^{28-30}$ Even though it is as such important, $14.5 \%$ of participants among discussed did not disclose their result. Consistent with other studies communicating with partner about testing prior to seeking service was found to be a predictor to disclosure. ${ }^{18}$ This might help individuals to anticipate partner's reaction and would give them an opportunity to raise the issue again and tell their result.

In this analysis it was observed that there was high agreement between anticipated and actual positive outcomes of disclosure among participants who anticipated supportive outcome to disclosure while $92 \%$ received support and assurance from their partner. From those $(14 \%)$ anticipated their partner would assure them and in actual terms $21.7 \%$ received assurance from their partners. However, some of the partners reacted with unwanted reaction such as anger $2.3 \%$, confused $19.7 \%$ and leave the relationship $0.2 \%$.

Even though there were eight participants who anticipated physical violence, there were only three individuals physically harmed. There was high agreement observed between anticipated and actual positive outcome of disclosure those individual who anticipated supportive outcome to disclosure who received support and assurance from their partner. In contrast there was no agreement between anticipated and actual negative outcomes of disclosure.

Finally in this study $2.1 \%$ of HIV positive women live in discordant relation and $8.1 \%$ of these couples do not mutually know their HIV status. Disclosure has paramount importance in curbing the infection. I suggest that HIV prevention should target HIV status disclosure and further behavioural change. Unless HIV positive individuals mutually know their HIV status it is difficult to use protective methods to prevent further transmission. In addition in this study substantial proportion of HIV infected individuals continue to have unprotected sex. This cross-sectional study is conducted in institutional basis and limits the ideas of those who were in their home during data collection which is considered as limitation of the study.

\section{Conclusion}

This study indicated that the outcomes of disclosure are encouraging but it is not that much satisfactory. The rate of HIV positive status disclosure to partner in this study is almost comparable with rate seen in other developing countries in recent years. Knowing partner's HIV status, couple counselling, discussing with partner about HIV and talking about HIV testing with partner prior to test were found to be main predictors for HIV status disclosure to partner. However, fear of partner's reaction, anticipated physical violence as a result of disclosure identified as a main barriers to disclosure of their status. Thus, due emphasis should be given to awareness creation and counselling on mutual disclosure, couple communication about HIV testing and legal support for women. Further, more multi-centred research on disclosure is needed to assess the context of disclosure in more detail.

\section{Acknowledgments}

First and for most we give honour to God and next the deepest gratitude could be given to Dr. Tegbar Yegzaw, Mr. Teklu Lemma, and Mr. Kassahun Bedlu for their willingness to encourage and support us through the process of this study. At last but least, our deepest gratitude goes to all who assisted us in providing relevant literature references in particular the Bole 17 health centre delivery ward staffs, mother support groups and librarians in AIDS resource centres.

\section{Funding}

None.

\section{Conflicts of interest}

The authors declare that they have no competing interests.

\section{References}

1. World Health Organization. HIV status disclosure to sexual partners: rates, Barriers and outcomes for women. 2004.

2. Makin JD, Forsyth BWC, Visser MJ, et al. Factors affecting disclosure in south african hiv-positive pregnant women. AIDS Patient Care and STDs. 2008;22(11):907-916.

3. WHO, UNAIDS. A progress report on the global plan towards the elimination of new HIV infections among children by 2015 and keeping their mothers alive. 2012.

4. Central statistical Agency (CSA). Ethiopian demography and health survey, Addis Ababa. Calverton Maryland, USA: ICF international; 2011.

5. Business Leadership Council. For a generation born HIV free; End the transmission of HIV from mother to children. 2012

6. Igwegbe AO, Ugboaja JO. Rate and correlates of HIV serostatus disclosure among HIV positive pregnant women in Nnewi south eastern Nigeria. Journal of Medicine and Medical science. 2010;1(7):296-301.

7. Gemechu E, Cherie A, Asfaw T. Disclosure experience to partner and its effect on intention to utilize prevention of mother to child transmission 
service among HIV positive pregnant women attending antenatal care in Addis Ababa, Ethiopia. BMC Public Health. 2013;13:765.

8. Medley A, Garcia-Moreno C, McGill S, et al. Rates, barriers and outcomes of HIV serostatus disclosure among women in developing countries: implications for prevention of mother-to-child transmission programmes. Bull World Health Organ. 2004;82(4):299-307.

9. Roxby AC, Matemo D, Drake AL, et al. Pregnant women and disclosure to sexual partners after testing HIV-1-seropositive during antenatal care. AIDS Patient Care and STDs. 2013;27(1):33-37.

10. Maricianah A Onono, Craig R Cohen, Mable Jerop, et al. HIV serostatus and disclosure: implications for infant feeding practice in rural south Nyanza, Kenya. BMC Public Health. 2014;14:390.

11. WHO. Use of antiretroviral drugs for treating pregnant women and preventing HIV infection in infants. 2012

12. Berhan Z, Abebe F, Gedefaw M, et al. Risk of HIV and associated factors among infants born to HIV positive women in Amara region, Ethiopia: a retrospective study. BMC Research Notes. 2014;7:876.

13. Walcott M, Hatcher A, Kwena Z, et al. Facilitating HIV status disclosure for pregnant women and partners in rural Kenya: a qualitative study. BMC Public Health. 2013;13:1115.

14. Federal Democratic Republic of Ethiopia MOH. Country progress report on HIV/AIDS response. Ethiopia: FMOH; 2012.

15. Obermeyer CM, Baijal P, Pegurri E. Facilitating HIV disclosure across diverse settings: a review. Am J Public Health. 2011;101(6):1011-1023.

16. Deribe K, Woldemichael K, Wondafrash M, et al. Disclosure experience and associated factors among HIV positive men and women clinical service users in southwest Ethiopia. BMC Public Health. 2008;8:81.

17. Mucheto P, Chadambuka A, Shambira G, et al. Determinants of nondisclosure of HIV status among women attending the prevention of mother to child transmission programme, Makonde district, Zimbabwe, 2009. Pan Afr Med J. 2011;8:51.

18. Deribe K, Lingerh W, Dejene Y. Determinants and outcomes of disclosing HIV-sero positive status to sexual partners among women in Mettu and Gore towns, Illubabor Zone southwest Ethiopia. Ethiop J Heal Dev. 2005;19(5):126-131

19. Erku TA, Megabiaw B, Wubshet M. Predictors of HIV status disclosure to sexual partners among People living with HIV/AIDS in Ethiopia. Pan Afr Med J. 2012;13:87.
20. Central statistical Agency of Ethiopia. The 2007 population and housing census of Ethiopia. 2008

21. Gari T, Habte D, Markos E. HIV positive status disclosure to sexual partner among women attending ART clinic at Hawassa University Referral Hospital, SNNPR, Ethiopia. Ethiop J Health Dev. 2010;24(1).

22. Batte A, Katahoire AR, Chimoyi A, et al. Disclosure of HIV test results by women to their partners following antenatal HIV testing: a populationbased cross-sectional survey among slum dwellers in Kampala Uganda. BMC Public Health. 2015;15:63.

23. Adeniyi OV, Ajayi AI, Selanto-Chairman N, et al. Demographic, clinical and behavioural determinants of HIV serostatus non-disclosure to sex partners among HIV-infected pregnant women in the Eastern Cape, South Africa. PLoS ONE. 2017;12(8):e0181730.

24. Nyandat J, Rensburg G Van. Non-disclosure of HIV-positive status to a partner and mother-to-child transmission of HIV: Evidence from a case control study conducted in a rural county in Kenya. South Afr J HIV Med. 2015;18(1):1-10.

25. Yaya I, Saka B, Landoh DE, et al. HIV status disclosure to sexual partners among people living with HIV and AIDS on antiretroviral therapy at Sokodé Regional Hospital Togo. PLoS One. 2015;215:1-9.

26. Yonah G, Fredrick F, Leyna G. HIV serostatus disclosure among people living with HIV/AIDS in Mwanza, Tanzania. AIDS Research and Therapy. 2014;11:5.

27. Alema HB, Yalew WA, Beyene MB, et al. HIV positive status disclosure and associated factors among HIV positive adults in Axum health facilities, Tigray, Northern Ethiopia. Science Journal of Public Health. 2015;3(1):61-66

28. Alemayehu M, Aregay A, Kalayu A, et al. HIV disclosure to sexual partner and associated factors among women attending ART clinic at Mekelle hospital, Northern Ethiopia. BMC Public Health. 2014;14:746.

29. Elizabeth S Kiula, Damian J Damianand, Sia E Msuya. Predictors of HIV serostatus disclosure to partners among HIV-positive pregnant women in Morogoro, Tanzania. BMC Public Health. 2013;13:433.

30. Shikwane ME, Villar-Loubet OM, Weiss SM, et al. HIV knowledge, disclosure and sexual risk among pregnant women and their partners in rural South Africa. Sahara J. 2013;10(2):105-112. 